\title{
FRACIONAMENTO DE ÓLEO ESSENCIAL CÍTRICO MODELO EM EQUIPAMENTO CONTÍNUO: ANÁLISE DE DESEMPENHO DO PROCESSO
}

\author{
D. GONÇALVES ${ }^{1}$, M. E. E. TESCHKE ${ }^{1}$, C. E. C. RODRIGUES ${ }^{1}$ \\ ${ }^{1}$ Universidade de São Paulo, Faculdade de Zootecnia e Engenharia de Alimentos, Departamento de \\ Engenharia de Alimentos, Laboratório de Engenharia de Separações \\ E-mail para contato: danielg@usp.br
}

\begin{abstract}
RESUMO - A obtenção de dados experimentais de fracionamento de óleos essenciais em equipamento contínuo é interessante para possibilitar uma futura aplicação industrial. $\mathrm{O}$ desempenho do equipamento Perforated Rotating Disc Contactor (PRDC) empregado para fracionamento da mistura limoneno + linalol, utilizando a mistura etanol + água como solvente, foi analisado em termos do índice de extração dos compostos (limoneno e linalol) e grau de concentração do linalol na fase extrato, em função de algumas variáveis de processo. Foi observado que o aumento da concentração de linalol na alimentação e a utilização de maiores razões entre as vazões mássicas de solvente e alimentação ocasionaram aumento dos índices de extração dos componentes. $\mathrm{O}$ aumento do teor de água no solvente acarretou na diminuição do índice de extração do limoneno e linalol e aumento do teor de linalol na fase extrato (em base livre de solvente).
\end{abstract}

\section{INTRODUÇÃO}

Óleos essenciais são matérias-primas de origem vegetal utilizadas principalmente, em indústrias de alimentos e indústrias químicas, como agentes aromatizantes e como ingredientes de fragrâncias em sabões, detergentes, cremes, loções, perfumes etc. (CHÁFER et al., 2005). Estes materiais tratamse de misturas complexas de centenas de componentes, sendo basicamente compostos por hidrocarbonetos e seus derivados oxigenados (KOSHIMA et al., 2012).

Os hidrocarbonetos são componentes não polares e insaturados e, por este motivo, são susceptíveis à reações de degradação, como polimerização (formação de resinas), rancificação ou oxidação por exposição ao ar e à luz. Esta deterioração resulta em off-flavor e pode ocasionar mudanças sensoriais drásticas no aroma original do óleo (HAYPEK et al., 2000). Os componentes oxigenados, por sua vez, são geralmente considerados preferíveis pelo odor e, devido este fato, seu conteúdo se tornou um parâmetro definitivo do estabelecimento do preço do óleo essencial, representando maior estabilidade e qualidade sensorial (GONÇALVES et al., 2014).

Dessa forma, com o intuito de melhorar a qualidade dos óleos essenciais, alguns processos têm sido desenvolvidos para enriquecer a mistura de compostos oxigenados com a remoção parcial de hidrocarbonetos terpênicos, principalmente do limoneno, favorecendo a estabilidade do óleo e consequentemente, aumentando seu valor comercial (SEVGILI et al., 2008). Este processo de retirada 


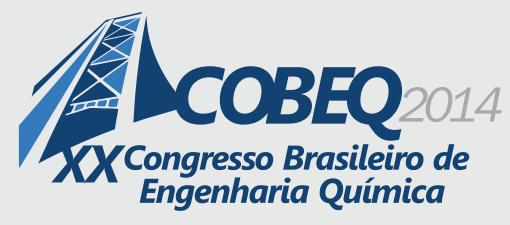

dos terpenos é conhecido como "desterpenação".

Todavia, a preparação de óleos essenciais com um alto teor de compostos oxigenados apresenta algumas dificuldades devido às suas características delicadas. A aplicação de calor pode afetar as propriedades sensoriais do óleo essencial e, por este motivo, um processo que evite tais dificuldades seria muito útil. Dentre as diversas técnicas empregadas no fracionamento de óleos essenciais, a extração líquido-líquido (ou extração com solvente) merece destaque, uma vez que pode ser realizada em temperatura ambiente e pressão atmosférica, tornando-se um processo alternativo interessante, por se tratar de um método de baixo impacto nas características sensoriais da matéria-prima e baixo consumo energético (KOSHIMA et al., 2012; GONÇALVES et al., 2014).

Com base nas informações supramencionadas, o presente trabalho visou estudar o desempenho do processo de desterpenação de óleos essenciais cítricos em um equipamento contínuo em escala laboratorial (Perforated Rotating Disc Contactor, ou Coluna de Discos Rotativos Perfurados), operando de modo contínuo e contracorrente. O óleo essencial cítrico foi preparado por meio de misturas de limoneno (representante da porção de hidrocarbonetos) e linalol (representante da porção dos oxigenados) em diferentes proporções e como solvente foram utilizados misturas de etanol e água. A análise de desempenho consistiu na determinação de alguns parâmetros, tais como índice de extração dos compostos presentes no óleo essencial e grau de concentração de linalol.

\section{MATERIAIS E MÉTODOS}

\subsection{Materiais}

Para a preparação da mistura modelo de óleo essencial cítrico foram utilizadas massas conhecidas de limoneno (Sigma-Aldrich, 97-98\%, CAS 5989-27-5, EUA) e linalol (Sigma-Aldrich, 97\%, CAS 78-70-6, EUA) em três proporções (5, 10 e $15 \%$ de linalol, em massa). O solvente hidroalcoólico foi preparado por meio da adição de água ultra pura (Millipore, modelo 3UV, França) ao etanol absoluto (Merck, 97,8\%, CAS 64-17-5, Alemanha), em duas proporções (30 e 40 de água, em massa).

\subsection{Métodos}

Experimentos de extração em Coluna de Discos Rotativos Perfurados (PRDC): Foram realizados diversos experimentos de fracionamento da mistura modelo, nos quais foram variadas a velocidade de rotação dos discos $(150,200$ e $250 \mathrm{rpm})$, o teor de soluto (linalol) na alimentação $(5,10$ e $15 \%$, em massa) e razão entre as vazões mássicas das correntes de solvente e alimentação $\mathrm{S} / \mathrm{F}(0,5$; $1,25 ; 2,5$ e 3,0$)$. Para os experimentos variando-se a velocidade de rotação dos discos utilizou-se alimentação com $5 \%$ de linalol (valor nominal, em massa) e razão S/F igual a 1,25 (valor nominal). Para os experimentos nos quais foi avaliada a influência da composição da alimentação adotou-se velocidade de rotação dos discos igual a $150 \mathrm{rpm}$ e razão $\mathrm{S} / \mathrm{F}$ igual a 1,25 (valor nominal). Já para os experimentos variando-se a razão $\mathrm{S} / \mathrm{F}$, foi utilizado alimentação com $5 \%$ de linalol (valor nominal, em massa) e velocidade de rotação dos discos igual a $150 \mathrm{rpm}$. Em todos os experimentos o solvente foi estabelecido como fase contínua e a alimentação (óleo essencial modelo) foi estabelecida como 
fase dispersa. $\mathrm{O}$ equipamento operou de forma contínua e em contracorrente à temperatura controlada de 25,0 $\pm 0,1{ }^{\circ} \mathrm{C}$ e pressão ambiente. Todos os experimentos foram realizados pelo menos em duplicata.

O equipamento consistiu em quatro correntes, sendo duas de entrada e duas de saída. As correntes de entrada foram: alimentação $(\mathrm{F})$ e solvente $(\mathrm{S})$; já as correntes de saída foram: extrato $(\mathrm{E})$, caracterizada por ser rica em solvente e compostos extraídos da alimentação e rafinado (R), caracterizado por ser rico em óleo essencial e uma pequena porção de solvente. Devido à densidade das fases, a alimentação (menos densa que o solvente) foi inserida na região inferior da coluna e a corrente de extrato, por sua vez, foi retirada na região inferior.

Determinação do teor de etanol, limoneno e linalol por CG-DIC: A composição das correntes rafinado e extrato, provenientes dos experimentos de extração na coluna PRDC, foi analisada por cromatografia gasosa com detector de ionização de chama (CG-DIC). A quantificação de etanol, limoneno e linalol foi realizada por meio de curvas de calibração construídas para cada componente. As condições experimentais utilizadas foram: coluna DBFFAP 0,25 $\mu \mathrm{m}, 30 \mathrm{~m}$ x 0,25 mm d.i. (Agilent, EUA); hélio como gás de arraste na taxa de $1,13 \mathrm{~mL} / \mathrm{min}$; temperatura do injetor de $250{ }^{\circ} \mathrm{C}$; temperatura da coluna de $(100$ a 240$){ }^{\circ} \mathrm{C}\left(\right.$ taxa de $\left.8{ }^{\circ} \mathrm{C} / \mathrm{min}\right)$; temperatura do detector de $280{ }^{\circ} \mathrm{C}$. Todas as quantificações foram realizadas no mínimo em duplicata e utilizou-se o 1-propanol como solvente cromatográfico (GONÇALVES et al., 2014).

Determinação do teor de água: O teor de água no solvente, etanol, limoneno e linalol, bem como nas fases provenientes do equipamento PRDC foi determinado pelo método de titulação Karl Fischer. Amostras de 0,01 a 0,1 g foram tituladas com solução de Karl Fischer (KF) utilizando-se como solvente metanol/clorofórmio na proporção 4:1, em volume. O título do reagente KF utilizado foi determinado no início de cada titulação e a porcentagem mássica de água nas amostras foi fornecida automaticamente pelo aparelho.

\subsection{Cálculos}

Visando a melhor compreensão do processo de desterpenação por extração com solvente no equipamento do tipo PRDC, foram calculadas a porcentagem total de linalol e limoneno extraídos da mistura modelo (\%Ext LOL e \%Ext LIM) e a composição de linalol na fase extrato em base livre de solvente $(\% L E)$. Estes índices estão apresentados nas Equações 1, 2 e 3 respectivamente.

$$
(\% \text { Ext } L O L)=\frac{E \cdot w_{2, E}}{F \cdot w_{2, F}} \times 100
$$

Na qual $E \cdot w_{2, E}$ e $F \cdot w_{2, F}$ tratam-se das vazões mássicas de linalol no extrato e na alimentação respectivamente $[\mathrm{g} / \mathrm{min}]$.

$$
(\% E x t L I M)=\frac{E \cdot w_{1, E}}{F \cdot w_{1, F}} \times 100
$$


Na qual $w_{1, E}$ e $w_{1, F}$ são frações mássicas de limoneno no extrato e na alimentação respectivamente.

$$
(\% L E)=\frac{E \cdot w_{2, E}^{\prime}}{\left(E \cdot w_{2, E}^{\prime}+E \cdot w_{1, E}^{\prime}\right)} \times 100
$$

$\mathrm{Na}$ qual $w_{2, E}^{\prime}$ e $w_{1, E}^{\prime}$ tratam-se das frações mássicas de linalol e limoneno no extrato, respectivamente, expressos em base livre de solvente.

\section{RESULTADOS E DISCUSSÃO}

A Figura 1 apresenta os valores dos índices de extração (\%Ext LOL, \%Ext LIM e \%LE) em função das variáveis estudadas, tais como velocidade de rotação dos discos (Figura 1a), teor de soluto (linalol) na alimentação (Figura 1b), razão entre as vazões mássica de solvente e alimentação (Figura 1c) e teor de água no solvente.

Segundo descrito por diversos autores, o aumento da velocidade de rotação dos discos promove diminuição do tamanho das gotículas da fase dispersa e, consequentemente, aumento da troca mássica e aumento da eficiência de extração devido à maior área de troca mássica (SARUBBO et al., 2003, 2005; PINA e MEIRELLES, 2000; WANG et al., 2002). Porém, conforme pode ser observado na Figura 1a, em geral, a velocidade de rotação dos discos exerceu baixa influência nos índices de extração. Pode-se perceber que houve uma diminuição estatisticamente significativa do índice \%Ext $L O L$ com o aumento da velocidade de rotação dos discos, de 150 para 200 rpm utilizando-se o solvente $30 \%$ de água. Este fato pode ser devido à ocorrência de dispersão axial, ou seja, a alta rotação dos discos pode ter causado a formação de turbilhões, ocasionando cisões no escoamento das fases (mudança na direção dos fluxos) e consequente diminuição da transferência de massa (PINA e MEIRELLES, 2000).

A importância de se analisar dados de extração através do índice \%LE (Equação 3) é devido ao fato que, desta forma, pode-se comparar a composição de linalol antes do processo de desterpenação (composição da alimentação) com a composição de linalol após o fracionamento (fase extrato) em termos apenas dos componentes de interesse (limoneno e linalol), não considerando a presença de solvente na fase. No caso, o processo foi capaz de concentrar o valor da mistura de $5 \%$ de linalol para cerca de $40 \%$ com o solvente $30 \%$ e cerca de $57 \%$ com o solvente $40 \%$ (Figura 1a), ou seja, de fato houve fracionamento da mistura. 

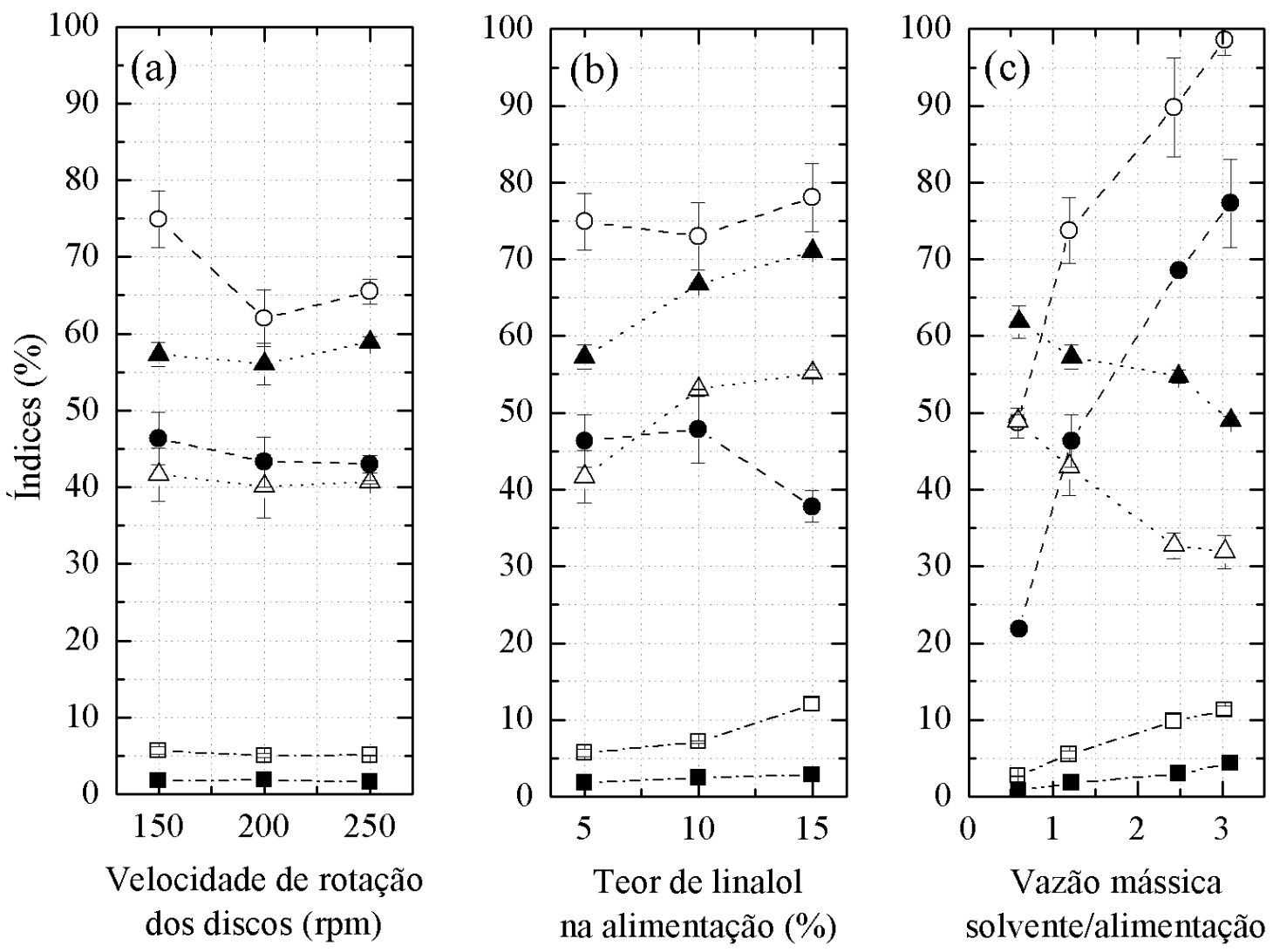

Figura 1 - Efeito das variáveis estudadas [(a) velocidade de rotação dos discos; (b) teor de linalol na alimentação; (c) razão entra as vazões mássicas de solvente e alimentação] sobre os índices: (-- $\bigcirc-$

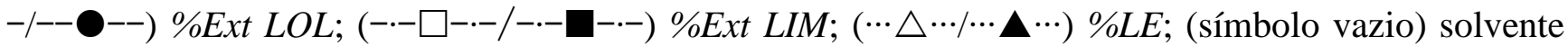
com $30 \%$ de água; (símbolo cheio) solvente com 40 \% de água. Valores nominais de água expressos em massa.

Em relação ao teor de linalol na alimentação, verifica-se que seu aumento acarreta no aumento mais expressivo dos valores de \%Ext LIM para o solvente com menor teor de água (30\% de água, em massa) e apresenta pouca influência nos valores de \%Ext LOL (Figura 1b).

$\mathrm{Na}$ Figura $1 \mathrm{~b}$ pode-se perceber que, mesmo com o aumento do \%Ext LIM, o teor de linalol na fase extrato, em base livre de solvente (\%LE) aumenta com o aumento do teor de linalol na alimentação. Seu aumento deve-se à maior quantidade de linalol presente na alimentação, e consequentemente, menor quantidade de limoneno. Sendo assim, mesmo com o aumento do índice de extração de limoneno, a porcentagem de extração de linalol permaneceu constante e, uma vez que o teor de linalol na alimentação aumenta, a fase extrato terá maior quantidade de linalol que limoneno, para a grande maioria dos ensaios realizados.

Com base nos resultados mostrados na Figura 1c, verifica-se que o aumento da razão entre as vazões mássicas de solvente e alimentação (S/F) acarreta no aumento dos índices \%Ext LOL e \%Ext 


\section{9 a 22 de outubro de 2014 \\ Florianópolis/SC}

LIM, atingindo um máximo de aproximadamente $100 \%$ de extração de linalol utilizando solvente $30 \%$ e razão $\mathrm{S} / \mathrm{F}=3,0$. Este fenômeno foi observado em estudo computacional realizado por Romero et al. (2010). Neste trabalho os autores reportaram que foi possível atingir um valor máximo de aproximadamente $100 \%$ de extração de linalol utilizando a razão $\mathrm{S} / \mathrm{F}=1,8$ e solvente 1,2-butanodiol. Arce et al. (2006) também estudaram, por simulação computacional, o processo de separação da mistura limoneno e linalol e relacionaram os índices de extração de linalol com a razão S/F para três solventes diferentes (buteno-1,4-diol, etileno-glicol e líquido iônico 1-etil-3-metilimidazolio metanossulfonato) e verificaram que, de fato, o aumento da razão S/F acarreta no aumento da porcentagem de extração do linalol.

Certamente, o aumento da quantidade de solvente no processo afeta fortemente a extração dos componentes presentes no óleo essencial. Uma vez que o limoneno apresenta-se como o componente majoritário do sistema, o aumento de sua extração, mesmo que pequena, acarreta no aumento significativo de sua concentração na fase extrato. Devido à isso, pode-se observar que o aumento da razão S/F implica na diminuição dos valores de \%LE (Figura 1c). Arce et al. (2006), através do estudo computacional, avaliaram a relação entre $\% L E$ e $\mathrm{S} / \mathrm{F}$ e verificaram que o aumento de $\mathrm{S} / \mathrm{F}$, de fato, ocasiona a diminuição de \%LE.

Em todos os casos, pode-se observar que e teor de água no solvente afetou de forma expressiva nos valores dos índices estudados, sendo que seu aumento acarretou na diminuição dos valores de \%Ext LOL e \%Ext LIM e aumento dos valores de \%LE. O aumento de \%LE se dá pela dimuição da extração do limoneno, que é o componente majoritário da mistura, sendo assim, mesmo com a diminuição da extração de linalol, sua concentração no extrato aumenta com o aumento do teor de água no solvente.

\section{CONCLUSÕES}

O aumento do teor de linalol na mistura e a utilização de maiores valores da razão entre as vazões mássicas de solvente e alimentação ocasionaram aumento dos índices de extração dos componentes. O teor de água no solvente afetou expressivamente os índices de extração dos componentes presentes na alimentação, sendo que em todos os casos o aumento da água no solvente acarretou na diminuição do índice de extração do limoneno e linalol e aumento do teor de linalol na fase extrato (em base livre de solvente).

De fato, o processo de fracionamento do óleo essencial no equipamento PRDC com solvente composto por etanol e água foi factível para o óleo essencial modelo (misturas de limoneno e linalol), sendo possivel a obtenção de frações concentradas no soluto (linalol). Dentre as diversas condições estudadas, a utilização de solvente com $40 \%$ de água e razão $\mathrm{S} / \mathrm{F}=0,5$ foi capaz de concentrar o linalol presente na alimentação em cerca de 12 vezes (de $5 \%$ para cerca de $62 \%$ ).

\section{AGRADECIMENTOS}

Os autores gostariam de agradecer à Fundação de Amparo à Pesquisa do Estado de São Paulo (FAPESP, processos 2013/11150-3, 2011/02476-7 e 2010/13286-1) pelo apoio financeiro. 


\section{9 a 22 de outubro de 2014 \\ Florianópolis/SC}

\section{REFERÊNCIAS}

ARCE, A.; MARCHIARO, A.; RODRÍGUEZ, O.; SOTO, A. Essential Oil Terpenless by Extraction using Organic Solvents or Ionic Liquids, AICHE J., v.52:6, p.2089-2097, 2006.

CHÁFER, A.; TORRE de la, J.; MUÑOZ, R.; BURGUET, M. C. Liquid-liquid Equilibria of the mixture linalool+ethanol+water at different temperatures. Fluid Phase Equilibri., v. 238, p.72-76, 2005.

GONÇALVES, D.; KOSHIMA, C. C.; NAKAMOTO, K. T.; UMEDA, T. K.; ARACAVA, K. K.; GONÇALVES, C. B.; RODRIGUES, C. E. C. Deterpenation of eucalyptus essential oil by liquid + liquid extraction: Phase equilibrium and physical properties for model systems at $\mathrm{T}=298.2 \mathrm{~K} . J$. Chem. Thermodyn., v. 69, p. $66-72,2014$.

HAYPEK, E.; SILVA, L. H .M.; BATISTA, E.; MARQUES, D. S.; MEIRELES, M. A. A.; MEIRELLES, A. J. A. Recovery of Aroma Compounds From Orange Essential Oil. Braz. J. Chem. Eng., v.17:4-7, p.705-712, 2000.

KOSHIMA, C. C.; CAPELLINI, M. C.; GEREMIAS, I. M.; ARACAVA, K.K.; GONÇALVES, C. B.; RODRIGUES, C. E. C. Fractionation of lemon essential oil by solvent extraction: Phase equilibrium for model systems at T = 298.2 K. J. Chem. Thermodyn., v. 54, p. 316-321, 2012.

PINA, C.G.; MEIRELLES, A.J.A. Deacidification of Corn Oil by Solvent Extraction in a Perforated Rotating Disc Column. J. Am. Oil Chem. Soc., v. 77, p. 553 - 559, 2000.

ROMERO, D.; DÍEZ, E., DÍAZ, I. Feasibility of 1,3-butanediol as solvent for limonene and linalool separation. Chem. Eng. Process., v. 49, p. 1183-1187, 2010.

SARUBBO, L. A.; OliVEIRA, L. A.; PORTO, A. L. F; TAKAKI, G. M. C. e TAMBOURGI, E. B. Performance of a perforated rotating disc contactor in the continuous extraction of a protein using the PEG-cashew-nut tree gum aqueous two-phase system. Biochem. Eng. J., v 16, p. 221-227, 2003.

SARUBBO, L.A.; OLIVEIRA, L.A.; PORTO, A.L.F.; CAMPOS-TAKAKI, G.M. E TAMBOURGI, E.B. Studies of Efficiency in a Perforated Rotating Disc Contactor Using a Polymer-Polymer Aqueous Two-Phase Systems. Braz. J. Chem. Eng., v. 22, p. 489 - 493, 2005.

SEVGILI, L. M.; SAHIN, S.; KIRBASLAR, S.I. Liquid-Liquid Equilibria of (Limonene + Linalool + Ethylene Glycol or Diethylene Glycol or Triethylene Glycol or 1,2-Propylene Glycol) Ternary Systems. J. Chem. Eng. Data, v. 53:3, p. 737-741, 2008.

WANG, Y. D.; FEI, W. Y.; SUN, J. H.; WAN, Y. K. Hydrodynamics and mass transfer performance of a modified rotating disc contactor (MRDC). Institution of Chemical Engineers. Trans IChemE, v. 80, Parte A, 2002. 